Original

\title{
Hepatocellular Carcinoma with PIVKA-II Production in a Young Laboratory Monkey
}

\author{
Katsuhiko Yoshizawa ${ }^{1,3}$, Yuji Oishi ${ }^{1}$, Koichi Sano ${ }^{1}$, Kenjiro Tsubota $^{1}$, \\ Kazuhiko Ikeda ${ }^{2}$, Yoshifumi Fukuhara ${ }^{2}$, Hideto Senzaki ${ }^{3}$, and Airo Tsubura ${ }^{3}$ \\ ${ }^{1}$ Department of Toxicologic Pathology, Toxicology Research Laboratories, and \\ ${ }^{2}$ Department of Toxicology, Toxicology Research Laboratories, Fujisawa Pharmaceutical Co., Ltd., Kashima 2-1-6, \\ Yodogawa, Osaka 532-8514, Japan \\ ${ }^{3}$ Department of Pathology II, Kansai Medical University, Fumizono-cho, Moriguchi, Osaka 570-8506, Japan
}

\begin{abstract}
Hepatocellular carcinoma which occurred in one male laboratory cynomolgus monkey at 5 years of age was investigated extensively by immunological, histopathological and electron-microscopic examinations. The animal exhibited no abnormalities in clinical laboratory tests including blood-chemistry, except for elevation of protein induced by vitamin $\mathrm{K}$ absence or antagonist II (PIVKA-II) in serum, which is one of the hepatic tumor markers. In virus antibody tests, the serum was positive for hepatitis A virus. On necropsy, a mass measuring $60 \times 60 \times 65 \mathrm{~mm}$ was seen in the hepatic left lobe. The tumor mass had a lobulated structure with hemorrhagic and necrotic areas, and was demarcated by thin fibrous capsules. Histopathologically, the tumor was composed of hepatocyte-like cells, having irregular trabecular structure with various thickness, lined by vascular endothelial cells. Cellular atypia such as polynucleated cells, mitotic figures, and invasion into the vascular cavity were also observed. Immunohistochemically, the tumor cells showed positive reaction for anti-PIVKA-II, anti-epithelial membrane antigen (EMA), anti-carcinoembryonic antigen (CEA), and anti-cytokeratin 18, as well as for proliferating cell nuclear antigen (PCNA). On electron-microscopic examination, the tumor cells had a number of tight junctions and formations of bile canaliculi between adjacent cells, basically resembling hepatocytes. This is the first case of hepatocellular carcinoma with PIVKA-II production in monkeys. Serological and immunohistochemical analyses for PIVKA-II are, therefore, practicable for diagnose as hepatocellular carcinoma in nonhuman primates. (J Toxicol Pathol 2002; 15: 61-68)
\end{abstract}

Key words: hepatocellular carcinoma, cynomolgus monkey, PIVKA-II, hepatitis virus, immunohistochemistry

\section{Introduction}

Although various spontaneous neoplasms have been reported in nonhuman primates, the incidence of neoplasms is very $\operatorname{low}^{1-3}$. In particular, spontaneous hepatic malignant neoplasms have rarely been described in monkeys; only fourteen tumors have been reported in wild or wild-derived aged monkeys (Table 1). The pathogenesis of spontaneous hepatocellular carcinoma (HCC) is not well-established in nonhuman primates due to its low incidence, though the occurrence is often associated with cirrhosis and hepatitis virus infection in humans ${ }^{12,13}$. Whereas several chemicals, such as 2-amino-3methylimidazo $[4,5-f]$ quinoline ${ }^{14}$, pyridoxine $e^{15}, \operatorname{cycasin}^{16}$,

Received: 29 November 2001, Accepted: 23 January 2002

Mailing address: Katsuhiko Yoshizawa, Department of Toxicologic

Pathology, Toxicology Research Laboratories, Fujisawa

Pharmaceutical Co., Ltd., Kashima 2-1-6, Yodogawa, Osaka

532-8514, Japan

TEL: 81-6-6390-1167 FAX: 81-6-6304-5716

E-mail: katsuhiko_yoshizawa@po.fujisawa.co.jp. aflatoxin $\mathrm{B}_{1}{ }^{17,18}$, and $\mathrm{N}$-nitrosodiethylamine ${ }^{19,20}$, can induce hepatic tumor in laboratory primates, only limited information is available from these experimentally-induced liver tumors in monkey. In the safety assessment of new chemicals or drugs, it is important to recognize spontaneous lesions in laboratory monkeys, especially in young monkeys that are routinely used in toxicological studies. In this report, we describe the occurrence of spontaneous hepatocellular carcinoma (HCC) in a young laboratory monkey and discuss the relevance to PIVKA-II production.

\section{Materials and Methods}

\section{Animal}

The male cynomolgus monkey (Macaca fascicularis), born and raised in primate colonies in Vietnam, was purchased from U.S.A. Covance Research Products at 4 years of age. The animal had been checked for one month for medical inspection and had no abnormal findings in the following examinations: parasite detection test, hematology and blood-chemistry, as well as serological tests for simian 
Table 1. Spontaneous Hepatocellular Tumors of Nonhuman Primates

\begin{tabular}{|c|c|c|c|c|c|}
\hline Hepatic Neoplasm & Species & No. of case & Age (years) & Authors (year) & Reference \\
\hline Hepatocellular carcinoma & Lemur macaco & 1 & unknown & O'Gara RW et al. (1972) & 2 \\
\hline Hepatocellular carcinoma & Cercocebus atys & 1 & $\fallingdotseq 10$ & Clark JD et al. (1973) & 4 \\
\hline Hepatocellular carcinoma & Tupaia belangeri & 2 & $\fallingdotseq 8$ & Hofmann W et al. (1981) & 5 \\
\hline Hepatocellular carcinoma & Pan troglodytes & 2 & $>7$ & Tabor E (1989) & 6 \\
\hline Hepatocellular carcinoma & Macaca mulatta, Tupaia belangeri & 3 & unknown & Beniasvili DS et al. (1990) & 7 \\
\hline Hepatocellular carcinoma & Pan troglodytes & 1 & 12 & Abe K et al. (1993) & 8 \\
\hline Hepatocellular carcinoma & Saimiri boliviensis & 1 & $>24$ & Borda JT et al. (1996) & 9 \\
\hline Hepatocellular carcinoma & Saimiri boliviensis & 1 & $>13$ & Morris TH et al. (1996) & 10 \\
\hline Hepatocellular carcinoma & Macaca fascicularis & 2 & $\fallingdotseq 5$ & Reindel JF et al. (2000) & 11 \\
\hline Hepatocellular carcinoma & Macaca fascicularis & 1 & $\overline{5}$ & $\begin{array}{l}-----\overline{-} \\
\text { Present case }\end{array}$ & \\
\hline Hepatocellular adenoma & Presbytis entellus & 1 & unknown & O'Gara RW et al. $(1972)$ & 2 \\
\hline Hepatocellular adenoma & $\begin{array}{l}\text { Presbytus entellus, } \\
\text { Cercopithecus aethiops, } \\
\text { Papio hamadryas, Macaca multa }\end{array}$ & 11 & unknown & Beniasvili DS et al. (1990) & 7 \\
\hline
\end{tabular}

Table 2. Virus Titers and Hepatic Tumor Markers

\begin{tabular}{lccc}
\hline & Present Case & Control Cases* & Method \\
\hline HAV & Inhibition $97.3 \%$ & Inhibition $90.2 \%$ & RIA \\
HBV & $<\times 16$ & $<\times 16$ & PA \\
HCV & $<0.1$ & $<0.1$ & RIA (C-100-3) \\
B-virus & negative & negative & RIA \\
HSV-1 & negative & negative & RIA \\
SIV & negative & negative & RIA \\
SRV & negative & negative & RIA \\
Filovirus & negative & negative & RIA \\
\hline AFP & $<0.5 \mathrm{ng} / \mathrm{mL}$ & $<0.5 \mathrm{ng} / \mathrm{mL}$ & RIA \\
PIVKA-II & $24770 \mathrm{mAU} / \mathrm{mL}$ & $122 \mathrm{mAU} / \mathrm{mL}$ & ECLIA \\
\hline
\end{tabular}

AFP: $\alpha$-fetoprotein, PIVKA-II: protein induced by vitamin $\mathrm{K}$ absence or antagonist II, HAV: hepatitis A virus, HBV: hepatitis B virus, HCV: hepatitis C virus, HSV-1: herpes simplex virus-1, SIV: simian immunodeficiency virus, SRV: simian retrovirus, *: three male untreated monkeys used in the same toxicity study, RIA: radio-immunoassay, ECLIA: electrochemiluminescence immunoassay, PA: peroxidase assay.

retrovirus, simian immunodeficiency virus, herpes B virus, herpes simplex virus type 1 , and simian T-lymphotrophic virus type 1 (Table 2). The animal was housed for about one year individually in a stainless steel cage in an environment of $25 \pm 1{ }^{\circ} \mathrm{C}$ room temperature, $60 \pm 5 \%$ relative humidity, and a $12 \mathrm{hr}$ light-dark cycle. The monkey was given daily $100 \mathrm{~g}$ of commercial diets in breeder and PS diets (Oriental Yeast Co., Ltd., Tokyo, Japan) in our laboratory and water freely. The present monkey was one of the monkeys employed in the low-dose group of a 4-week toxicity study of a certain test compound and the age was at 5 years of age. During the study period, animals were routinely observed for clinical signs, weighed, and examined for hematology and blood-chemistry. No abnormalities were detected in the liver of other monkeys except this monkey. Therefore, the study report concluded that the test compound had no hepatotoxicity potential. The monkey was handled in accordance with Fujisawa Pharmaceutical's ethical guidelines for animal care, handling, and termination.

\section{Serological test}

The concentrations of two markers for tumors of hepatocyte origin; vitamin $\mathrm{K}$ absence or antagonist II [PIVKA-II, ECLIA method, PIVKA-II IRMA Daiichi kit (Daiichi Radioisotope Labs, Tokyo, Japan) ${ }^{21}$ ] and alfafetoprotein [AFP, RIA method, Alfa-feto RIA beads kit (Dainabot, Tokyo, Japan) $^{22}$ ], and the antibody titers against hepatitis A [HAV, RIA method, HA antibody RIA kit (Dainabot) ${ }^{23}$, B [HBV, PA method, Cellodia anti-HBs PA kit (Fuji Rebio, Tokyo, Japan) $\left.{ }^{24}\right]$ and C [HCV, RIA method, Ortho-HCV Ab IRMA kit (Ortho-Clinical Diagnostics, Tokyo, Japan $)^{25}$ ] viruses were determined serologically (Table 2); it has been reported that PIVKA-II, which is an abnormal prothrombin with a relatively high incidence in HCC patients, is one of the useful tumor markers for human $\mathrm{HCC}^{21,26-30}$. These serological tests were performed at Falco 
Table 3. Immunohistochemical Profile of the Tumor Cells

\begin{tabular}{cccccc}
\hline Antibodies & Clone & Source & Dilution & Antigen retrieval & Results \\
\hline PIVKA-II & MU-3 & Eisai & 50 & microwave & Diffuse, ++ \\
Cytokeratin-18 & DC-10 & DAKO & 20 & microwave & Focal, + \\
CEA & polyclonal & DAKO & 150 & microwave & Diffuse, + \\
EMA & E29 & Nichirei & prediluted & NT & Focal, + \\
PCNA & PC-10 & Novacastra & 100 & microwave & Diffuse, ++ \\
Vimentin & V9 & DAKO & 40 & microwave & Negative \\
AFP & polyclonal & Nichirei & prediluted & NT & Negative \\
Factor VIII & F8/86 & Nichirei & prediluted & trypsin & Negative \\
Actin & HHF-35 & Enzo & 50 & microwave & Negative \\
p53 & DO-7 & Nichirei & prediluted & microwave & Negative \\
\hline
\end{tabular}

PIVKA-II: protein induced by vitamin $\mathrm{K}$ absence or antagonist II, CEA: carcinoembryonic antigen, EMA: epithelial membrane antigen, PCNA: proliferating cell nuclear antigen, AFP: $\alpha$-fetoprotein, NT: not treated, $+:$ positive, ++ : strongly positive.
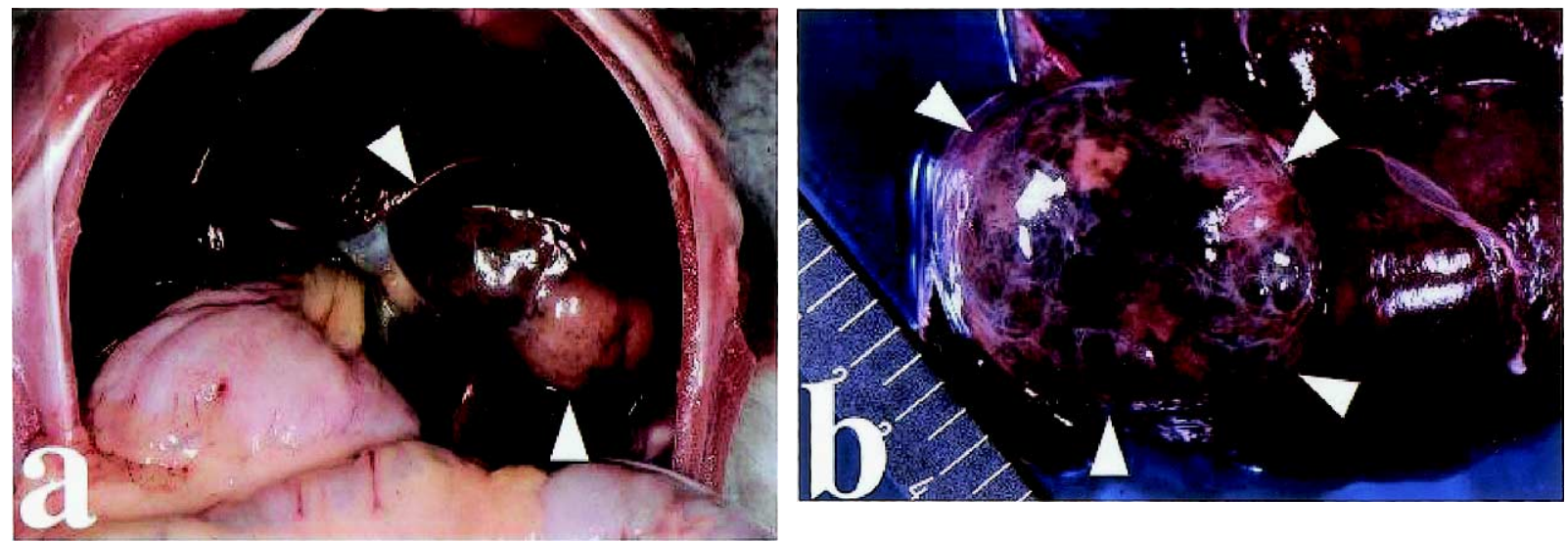

Fig. 1. Gross view of the liver. A large gray and dark red mass is located in the left lobe (a). The tumor is composed of multilobular structures covered by a thin fibrous capsule accompanied by hemorrhage and necrosis (b).

Biosystems Co., Ltd. (Kyoto, Japan) for blood sample obtained from the present monkey; sera from three male monkeys in the control group of the toxicity study served as the controls.

\section{Pathology}

The monkey was sacrificed under deep anesthesia by exsanguination from the cervical aorta and subjected to a complete necropsy including measurement of organ weights. Specimens of major organs were fixed in $10 \%$ buffered formalin, embedded in paraffin, sectioned, and stained with hematoxylin and eosin (HE) for routine histopathological examination. Additional serial sections of the hepatic tumor were stained with periodic acid-Schiff (PAS), azan, phosphotungstic acid hematoxylin (PTAH), silver reticulin, Berlin blue for iron, and Hall's method for bile. Representative sections were stained using immunocytochemical technique ${ }^{31-33}$ for PIVKA-II (MU-3, Eisai, Tokyo, Japan), cytokeratin 18 (CK18; DC-10, DAKO, Glostrup, Denmark), carcinoembryonic antigen (CEA; polyclonal, DAKO), epithelial membrane antigen (EMA; E29, DAKO), proliferating cell nuclear antigen (PCNA; PC10, Novocastra, Newcastle upon Tyne), vimentin (V9, DAKO), alfa-fetoprotein (AFP; polyclonal, DAKO), factor VIII-related antigen (F8/86, Nichirei, Tokyo, Japan), alfasmooth actin (HHF-35, Enzo, USA), and p53 (DO-7, Nichirei) (Table 3). Additionally, some specimens of the hepatic tumor were post-fixed in $2.5 \%$ glutaraldehyde and $1 \%$ osmium tetroxide solutions, then dehydrated in ethanol and embedded in Epon 812. Ultrathin sections were stained with uranyl acetate and lead citrate for electron-microscopic observation.

\section{Results}

\section{Clinical laboratory findings}

Clinical laboratory tests including hematology and blood-chemistry revealed no abnormalities before and during the study period. The terminal values before sacrifice in the parameters of hepatic damage; glutamic oxalacetic 

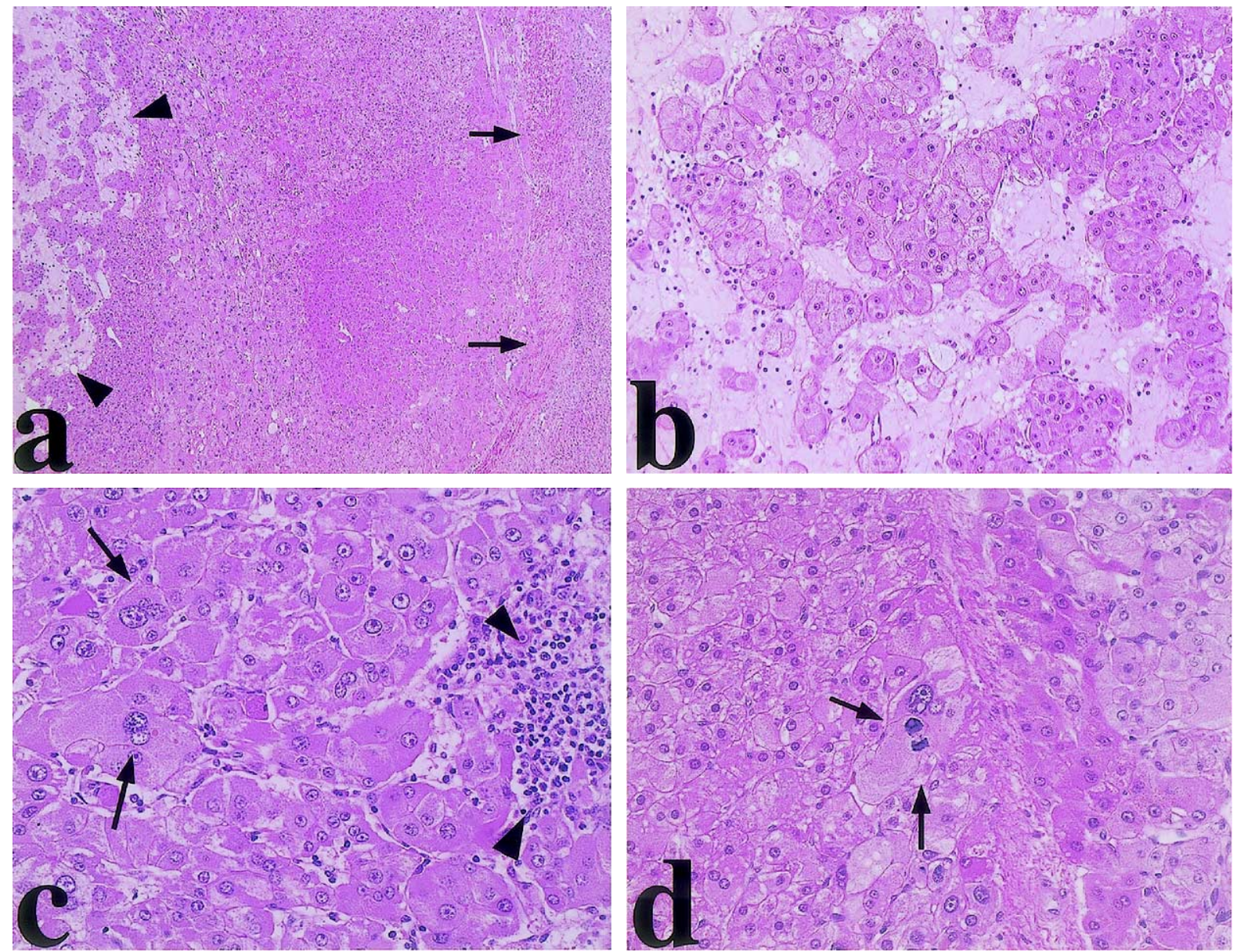

Fig. 2. Photomicrographs of the hepatic tumor. (a) Solid sheets and trabeculae of neoplastic hepatocytes are partially surrounded by a fibrous capsule (arrows). Dilated vascular spaces (arrow heads) are seen. HE staining, $\times 40$. (b) Trabeculae in various thickness are separated by sinusoids lined by endothelial cells. HE staining, $\times 100$. (c) Polynucleated giant cells with cellular pleomorphism in size and shape are seen (arrows). Focal lymphocytic infiltration is seen in sinusoidal area (arrow heads). HE staining, $\times 100$. (d) Note atypical mitotic figure of hepatic tumor cells. HE staining, $\times 100$.

transaminase (GOT), glutamic pyruvic transaminase (GPT) and alkaline phosphatase (ALP), were within the normal ranges $(36,28$, and $614 \mathrm{mU} / \mathrm{mL}$ respectively).

\section{Serological tests for viral antigen and hepatic tumor markers \\ Serum PIVKA-II concentration before sacrifice was elevated $(24770 \mathrm{mAU} / \mathrm{mL})$ compared with those of control levels (mean: 122, min: 106, max: $139 \mathrm{mAU} / \mathrm{mL}$ ), whereas the AFP value was similar to control levels (below $0.5 \mathrm{ng} /$ $\mathrm{mL}$ ) (Table 2). The history of HAV infection was suspected in these animals, since the virus antibody reaction before sacrifice was positive for HAV in this animal (inhibition rate $97.3 \%$ ) as well as in the control animals (inhibition rate $90.2 \%$ ), whereas they were negative for HBV and HCV.}

\section{Macroscopic findings}

The $60 \times 60 \times 65 \mathrm{~mm}$-large gray and dark red mass with hemorrhagic and necrotic areas was located in the hepatic left lobe (Fig. 1a, b). At the cut surface, the mass had a multilobular structure covered by a thin fibrous capsule. Emboli to hepatic portal vein were not seen, and grayish nests were detected in the other lobes (Fig. 1b). The gross abnormalities were not detected in any other organs or tissues.

\section{Histopathology}

The tumor consisted of solid sheets and trabeculae partially surrounded by a fibrous capsule (Fig. 2a). The trabeculae were of various thickness and separated by prominent sinusoids lined with vascular endothelial cells (Fig. 2b). Tumor cells were larger than adjacent normal hepatocytes and had abundant homogenous or vacuolated eosinophilic cytoplasm with well-demarcated cell borders. Collagen fibers were often detected between tumor cords by azan stain; however, reticulin fibers were rarely found by silver stain. Tumor cells had cellular pleomorphism in size and shape, and there were polynucleated giant cells with 

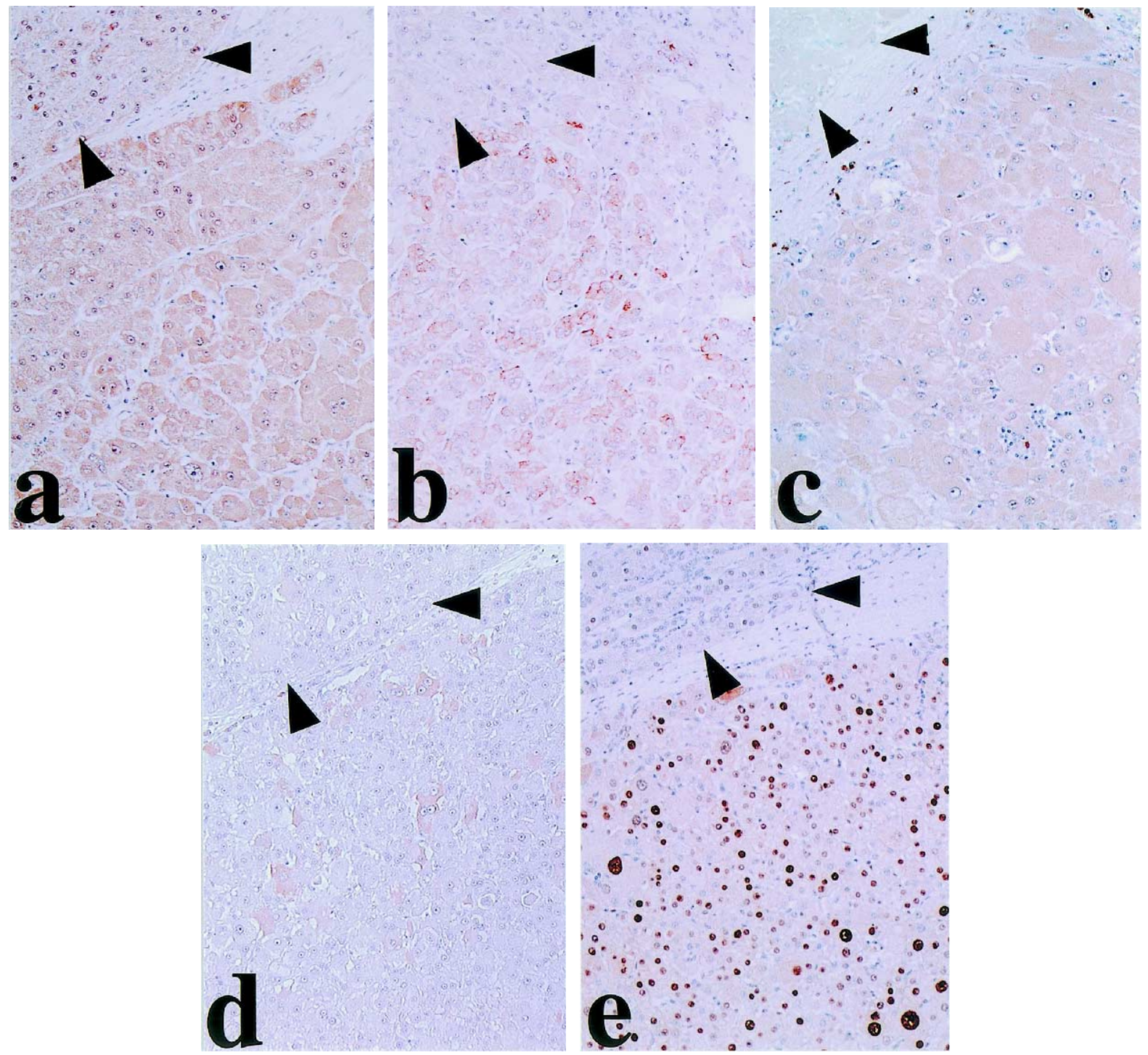

Fig. 3. Immunohistochemical characteristics of hepatic tumor. Most of the tumor cells are diffusely positive for PIVKA II (a). Scattered tumor cells are positive for CK18 (b), CEA (c), and EMA (d). Most tumor cells are highly labeled by PCNA (e). Arrow heads show normal area. Immunohistochemical staining, $\times 100$.

single or multiple nucleoli (Fig. 2c) and atypical mitotic figures (Fig. 2d). Tumor invasions to vascular cavities were infrequently observed and tumor cells rarely possessed PTAH-positive granules, so called pale bodies. Tumor cells forming glandular and ductal structures with bile production were not observed by Hall's stain. Moreover, the existence of bile ducts, Glisson's sheath or cirrhotic changes were seldom detected. Focal lymphocytic infiltration (Fig. 2c), hemosiderin deposition by Berlin blue stain, and calcified parasite in dilated vascular space of tumor necrotic area were observed.

The parenchyma surrounding the neoplasm was compressed and atrophic. In other lobes, no metastases were detected, although focal hepatocellular hypertrophy without compression of parenchyma was seen. In accordance with grayish nests observed macroscopically, focal glycogen-rich areas were detected by PAS-positive reaction. Additionally, the other organs and tissues were demonstrated to be normal for the animal's age in detailed histopathological examinations.

The results of immunohistochemical stain of the tumor are summarized in Fig. 3 and Table 3. Most neoplastic cells showed strongly positive reaction for PIVKA II (Fig. 3a), while several tumor cells were weakly positive for CK18 (Fig. 3b), CEA (Fig. 3c), and EMA (Fig. 3d). Moreover, high PCNA-labeling indicated high cellular proliferation activity in tumor cells (Fig. 3e). They were negative for vimentin, AFP, factor III, actin, and p53 (Table 3). In the normal area surrounding the neoplasm, some hepatocytes were weakly positive for PIVKA II. A few PCNA-labelled 


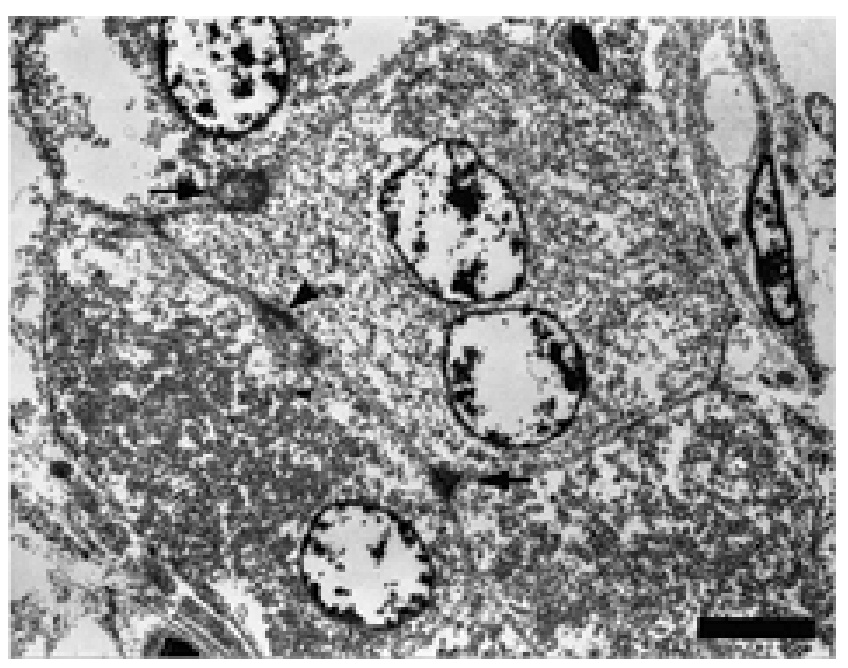

Fig. 4. Electron micrographs of tumor cells. Tight junction (arrow head) and structures resembling bile canaliculi (arrows) are seen between the carcinoma cells. bar: $6 \mu \mathrm{m}$.

cells in addition to bile duct epithelium were positive for CK18.

Electron-microscopically, tumor cells possessing one or two round nuclei had a high number of swollen mitochondria in the cytoplasm. Golgi apparatus, glycogen granules, and lipid droplets were also present in the cytoplasm. Between the tumor cells, tight junctions and structures resembling bile canaliculi were often observed (Fig. 4).

\section{Discussion}

The present case demonstrated typical features of hepatocellular carcinoma; trabecular proliferation with sinusoidal structure and vascular invasion of neoplastic cells. Moreover, electron-microscopic features such as junctional structure and bile canaliculi were suggestive of hepatocellular origin ${ }^{34}$. Based on the aforementioned findings and anatomical location, we diagnosed the tumor as hepatocellular carcinoma (HCC). Review of the literature (Table 1) revealed only fourteen cases of spontaneous hepatic malignant neoplasia in several strains of wild or wild-derived aged monkeys. Our case may be added to the limited number of reports on spontaneously-occurring hepatic tumors in young nonhuman primates.

The etiology of liver tumors in both human and animals documented in the literature includes cirrhosis, viral hepatitis, parasites, and aflatoxin in diet. In our case, there were no factors which suggested any relationship to the diet, because the same quality of commercial diet has been given to monkeys in breeder and our laboratory. Moreover, there were no cirrhotic changes in the liver. However, the history of HAV and parasitic infections in the liver was apparent by histopathological and immunological analyses in our case. It is well known that several species of healthy monkeys show detectable antibodies to HAV and $\mathrm{HBV}^{35}$; HAV does not seem to cause any hepatic lesions in nonhuman primates ${ }^{36}$, while HBV can induce subacute hepatitis but not neoplastic changes $^{36}$. On the other hand, HCV (non-A, non-B hepatitis virus) induces $\mathrm{HCC}$ experimentally in some species of monkeys ${ }^{6,37,38}$. The present case was not related to HBV and $\mathrm{HCV}$ infection as indicated by negative immunological reaction. Concerning the parasitic cause, $\mathrm{HCC}$ in a chimpanzee has been reported to be associated with chronic Schistosoma mansoni infection ${ }^{8}$. It was not clear whether the parasite infection was related to the occurrence of HCC in this animal, although calcified parasite in tumor necrotic area was observed.

It is generally accepted that PIVKA-II is a useful tumor marker for human $\mathrm{HCC}^{21,26-30}$. Although the exact mechanism of the elevation of PIVKA-II levels in HCC is not clear, abnormal prothrombin appears to be produced in relation to excessive synthesis of prothrombin precursors in human HCC tissue ${ }^{28}$. Moreover, it is also well recognized that AFP is produced by immature hepatocytes of the fetus or in hepatic tumors ${ }^{2}$. Both AFP and PIVKA-II are generally detected in the serum of advanced HCC patients; however, serum PIVKA-II levels do not correlate with serum AFP levels ${ }^{28-30}$. In our case, serum AFP level was within the normal range and AFP was not detected in tissues immunohistochemically. This finding agrees to the previous reports; though a progressive increase of serum AFP is seen in several cases of chemically-induced HCC in primates $^{14,15,19}$, neoplastic cells do not always show a positive reaction for AFP immunohistochemically ${ }^{11}$. In contrast, usefulness of immunohistochemical analyses for PIVKA-II has been reported in human HCC and ovarian hepatoid carcinoma $^{31,32}$. Our results suggest PIVKA-II may be a useful HCC marker in monkey HCC, as same as is the case in humans.

Immunohistochemical analyses of chemically-induced monkey HCC have revealed positive reactions for cytokeratin 8,18 , and/or $19^{20}$. In addition, spontaneous HCC is reported to be positive for glutathione S-transferase, AFP, and /or CEA ${ }^{11}$. Both tumor types were positive for CK18 antigen. In the present $\mathrm{HCC}$, neoplastic cells revealed positive reactions for CK18, EMA, and CEA, in line with previous reports in monkeys and humans ${ }^{11,12,20,38}$, but were negative for p53. p53 is a nuclear protein that normally regulates cell growth and suppresses tumor formation. Mutation of p53 has been documented in $50 \%$ of human HCC patients ${ }^{39}$ and in $20 \%$ of chemically-induced HCC monkeys ${ }^{40}$; however, the mutation did not occur in the present case, similarly to some other cases in primates ${ }^{40,41}$.

In chemically-induced tumors in monkeys, usefulness of PIVKA-II has not been widely recognized, yet, although some information characterized by serological, morphological and immunohistochemical data is available. The results of our young monkey case may serve as a useful reference for researchers who will encounter similar lesions in both veterinary and toxicological research in nonhuman primates. Moreover, the present report provides additional 
information on the fact that young monkeys such as 5 years of age have the potential for developing spontaneous hepatocellular carcinoma.

Acknowledgements: We thank Ms. T. Akamatsu at Kansai Medical University and Ms. Y. Morioka at Fujisawa Pharmaceutical Co., Ltd. for their skillful technical assistance.

\section{References}

1. Lapin BA. Use of nonhuman primates in cancer research. J Med Primatol 1982; 11: 327-341.

2. O'Gara RW and Adamson RH. Spontaneous and induced neoplasms in nonhuman primates. In: Pathology of Simian Primates, part I, TW Fiennes (ed), New York: Basel, 190238, 1972.

3. Thorgeirsson UP, Dalgard DW, Reeves J, and Adamson RH. Tumor incidence in a chemical carcinogenesis study of nonhuman primates. Reg Toxicol Pharm 1994; 19: 130-151.

4. Clark JD and Olsen RE. Hepatoma in a mangabey (cercocebus atys). Vet Pathol 1973; 10: 89-93.

5. Hofmann W, Moller P, Schwaier A, Flugel RM, Zoller L, and Darai G. Malignant tumors in tupaia (tree shew). J Med Primatol 1981; 10: 155-163.

6. Tabor E. Nonhuman primate models for non-A, non-B hepatitis. Cancer Detect Prev 1989; 14: 221-225.

7. Beniashvili DS. Tumors of the liver, bile ducts, and gallbladder. In: Experimental Tumors in Monkeys, DS Beniashvili (ed), Boca Raton: CRC press, 26-42, 1990.

8. Abe K, Kagei N, Teramura Y, and Ejima H. Hepatocellular carcinoma associated with chronic Schistosoma mansoni infection in a chimpanzee. J Med Primatol 1993; 22: 237239.

9. Borda JT, Ruiz JC, and Sanchez-Negrette M. Spontaneous hepatocellular carcinoma in Saimiri boliviensis. Vet Pathol 1996; 33: 724-726.

10. Moriss TH and Abdi MM. Hepatocellular carcinoma in a squirrel monkey (Saimiri sciureus). J Med Primatol 1996; 25: $137-139$.

11. Reindel JF, Walsh KM, Toy KA, and Bobrowski WF. Spontaneous occurring hepatocellular neoplasia in adolescent cynomolgus monkeys (Macaca fascicularis). Vet Pathol 2000; 37: 656-662.

12. Ishak KG, Anthony PP, and Sobin LH. Hepatocellular carcinoma (liver cell carcinoma). In: Histological Typing of Tumors of the Liver, 2nd ed., KG Ishak, PP Anthony, and LH Sobin (eds), Heidelberg: Springer-Verlag, 11-17, 1994.

13. Liver Cancer Study Group of Japan (eds). The general rules for the clinical and pathological study of primary liver cancer. Kinbara, Tokyo, 1992 (in Japanese).

14. Adamson RH, Thorgeirsson UP, Snyderwine EG, Thorgeirsson SS, Reeves J, Dalgard DW, Takayama S, and Sugimura T. Carcinogenicity of 2-amino-3methylimidazo[4,5-f]quinoline in nonhuman primates: induction of tumors in three macaques. Jpn J Cancer Res 1990; 81: 10-14.

15. Foy H, Kondi A, Davies JNP, Anderson B, Parker A, Preston J, and Peers FG. Histologic changes in livers of pyridoxine-deprived baboons-relation to alpha1 fetoprotein and liver cancer in Africa. J Natl Cancer Inst 1974; 53:
1295-1311.

16. Sieber SM, Correa P, Dalgard DW, Mclntire KR, and Adamson RH. Carcinogenicity and hepatotoxicity of cycasin and its aglycone methylazoxymethanol acetate in nonhuman primates. JNCI 1980; 65: 177-189.

17. Gopalan C, Tulpule PG, and Krishnamurthi D. Induction of hepatic carcinoma with aflatoxin in the rhesus monkey. Fd Cosmet Toxicol 1972; 10: 519-521.

18. Reddy JK, Svoboda DJ, and Rao MS. Induction of liver tumors by aflatoxin B1 in the tree shrew (Tupaia glis), a nonhuman primate. Cancer Res 1976; 36: 151-160.

19. Hull EW, Carbone PP, Gitlin D, O'Gara RW, and Kelly MG. $\alpha$-Fetoprotein in monkeys with hepatoma. J Nat Cancer Inst 1969; 42: 1035-1044.

20. Lapis K, Sarosi I, Bocsi J, and Thorgeirsson UP. Cytokeratin patterns of liver carcinomas induced by diethylnitrosamine in monkeys. Lab Invest 1995; 72: 748-759.

21. Sakizono K, Oita T, Shibata Y, Tamura A, and Kasakura S. Clinical usefulness of serum PIVKA-II levels determined by ECLIA system as a tumor maker for hepatocellular carcinoma. Jpn J Clin Pathol 1998; 46: 936-941 (in Japanese).

22. Oikawa S, Totsuka T, and Ishikawa K. Bizu-kosouhou niyoru AFP RIA Kit III no kento. Gendaiiryo 1982; 14: 720726 (in Japanese)

23. Kouseisho Tokuteishikkan "Nanchisei no Kanen" group. RIAhou (HAVAB) niyoru kecyuu HA-koutai sokutei no kento. Igakutoyakugaku 1980; 3: 101-104 (in Japanese).

24. Kamachi M, Masumitsu K, Nakao T, Suzuki Y, Suzuki H, and Sekiguchi S. HBs-kougen oyobi koutai sokutei niokeru zerachinryushi gyousyuhou no kento. Rinsyoukensashiyaku 1994; 17: 1173-1180 (in Japanese).

25. Tanaka E, Kiyosawa K, Furuta S, Matsushima K, Hino K, Ino S, Yasuda K, Kuroki T, Akaba K, and Suzuki H. Measurement and quantification of hepatitis $\mathrm{C}$ virus related C100-3 antibody by radioimmunoassay kit. Kantansui 1990; 21: 1189-1196 (in Japanese).

26. Liebman HA, Furie BC, Tong MJ, Blanchard RB, Lo KJ, Lee SD, Coleman MS, and Furie B. Des- $\gamma$-carboxy (abnormal) prothrombin as a serum marker of primary hepatocellular carcinoma. N Engl J Med 1984; 310: 14271431.

27. Fujiyama S, Morishita T, Hashiguchi O, and Sato T. Plasma abnormal prothrombin (des- $\gamma$-carboxy prothrombin) as a marker of hepatocellular carcinoma. Cancer 1988; 61: 16211628.

28. Tanaka Y, Kashiwagi T, Tsutsumi H, Nagasawa M, Toyama T, Ozaki S, Naito M, Ishibashi K, and Azuma M. Sensitive measurement of serum abnormal prothrombin (PIVKA-II) as a marker of hepatocellular carcinoma. Hepatogastroenterol 1999; 46: 2464-2468.

29. Lamerz R, Runge M, Stieber P, and Meissner E. Use of serum PIVKA-II (DCP) determination for differentiation between benign and malignant liver diseases. Anticancer Res 1999; 19: 2489-2494.

30. Okuda H, Nakanishi T, Takatsu K, Saito A, Hayashi N, Watanabe K, Magario N, Yokoo T, and Naraki T. Measurement of serum levels of des- $\gamma$-carboxy prothrombin in patients with hepatocellular carcinoma by a revised enzyme immunoassay kit with increased sensitivity. Cancer 1999; 85: 812-818.

31. Tamano M, Sugaya H, Oguma M, Murohisa T, Tomita Y, 
Matsumura A, Kojima K, and Terano A. Immunolocalization of PIVKA-II in paraffin-embedded specimens of hepatocellular carcinoma. Liver 1999; 19: 406-410.

32. Senzaki H, Kiyozuka Y, Mizuoka H, Yamamoto D, Ueda S, Izumi $\mathrm{H}$, and Tsubura $\mathrm{A}$. An autopsy case of hepatoid carcinoma of the ovary with PIVKA-II production: immunohistochemical study and literature review. Pathol Int 1999; 49: 164-169.

33. Yoshizawa K, Oishi Y, Tsubota K, Ieoka K, Fujii T, Ohe O, Senzaki H, and Tsubura A. Latent infection of canine herpes virus in laboratory beagle dogs. J Toxicol Pathol 2000; 13: $1-6$.

34. Williams AO. Ultrastructure of liver cell carcinoma in Macaca mulata monkey. Exp Mol Pathol 1970; 13: 359-369.

35. Eichberg JW and Kalter SS. Hepatitis A and B: serologic survey of human and nonhuman primate sera. Lab Anim Sci 1985; 30: 541-543.

36. Kornegay RW, Giddens WE, Van Hoosier GL, and Morton WR. Subacute nonsuppurative hepatitis associated with hepatitis B virus infection in two cynomolgus monkeys. Lab Anim Sci 1985; 35: 400-404.
37. Muchmore E, Popper H, Peterson DA, Miller MF, and Lieberman HM. Non-A, non-B hepatitis-related hepatocellular carcinoma in a chimpanzee. J Med Primatol 1988; 17: 235-246.

38. Tabor E, Hsia CC, and Muchmore E. Histochemical and immunohistochemical similarities between hepatic tumors in two chimpanzees and man. J Med Primatol 1994; 23: 271279.

39. Hsia CC, Kleiner DE, Axiotis CA, Bisceglie AD, Nomura AMY, Stemmermann GN, and Tabor E. Mutations of p53 gene in hepatocellular carcinoma: roles of hepatitis B virus and aflatoxin contamination in the diet. J Natl Cancer Inst 1978; 84: 1638-1641.

40. Fujimoto Y, Hampton LL, Snyderwine EG, Nagao M, Sugimura T, Adamson RH, and Thorgeirsson SS. p53 gene mutation in hepatocellular carcinoma induced by 2-amino-3methylimidazo[4,5-f]quinoline in nonhuman primates. Jpn J Cancer Res 1994; 85: 506-509.

41. Fujimoto Y, Hampton LL, Luo LD, Wirth PJ, and Thorgeirsson SS. Low frequency of p53 gene mutation in tumors induced by aflatoxin B1 in nonhuman primates. Cancer Res 1992; 52: 1044-1046. 